\title{
Preliminary eValuation of primaquine activity ON RODENT MALARIA MODEL AFTER TRANSDERMAL ADMINISTRATION
}

\author{
MAYORGA P.*,**, DEHARO E.***, LANDAU I.*** \& COUARRAZE G.*
}

Summary :

The aim of this preliminary study was to investigate the potential use of the transdermal route for primaquine administration in the treatment of malaria. Thus the activity of this drug on asexual blood forms of two rodent malaria parasites (P. v. petteri and P. y. nigeriensis) was evaluated following a single TTS patch application. Sustained plasma concentration values were observed for about 60 hours. The results obtained from a prepatency test showed that primaquine was more active towards $P$. v. petteri than $P$. y. nigeriensis. This preliminary study showed that the transdermal route for primaquine administration may be a promising strategy for improving the treatment of malaria in both causal prophylactic and prevention of relapses infection.

KEY WORDS : primaquine, antimalarial activity, rodent malaria, percutaneous absorption, transdermal drug delivery system.

MOTS CLÉS : primaquine, antipaludéen, paludisme, rongeur, absorption percutanée, système transdermique
Résumé : Étude PRÉLIMINAIRE CHeZ LE RONGEUR DE L'ACTIVITÉ transdermiQue de la primaQuine sur des Plasmodilm

L'objectif de cette étude préliminaire a été l'évaluation des potentialités de la voie transdermique pour l'administration de la primaquine dans le traitement du paludisme. L'activité de ce principe actif sur les formes asexuées de deux espèces de parasites de rongeur (Plasmodium $v$. petteri et $\mathrm{P}$. y. nigeriensis) a été évaluée après application unique d'un système transdermique. Des valeurs relativement constantes de la concentration plasmatique de primaquine ont été observées pendant environ 60 heures. Les résultats obtenus dans le test de prépatence montrent que la primaquine est plus active contre P. v. petteri que $P$. y. nigeriensis. Cette étude préliminaire a mis en évidence que la voie transdermique pour l'administration de la primaquine peut être une stratégie très prometteuse pouvant contribuer à l'amélioration du traitement du paludisme en termes prophylactiques ou bien dans la prévention de rechutes tardives à la suite d'une infection.

\section{INTRODUCTION}

T he goal of this work was the evaluation of the transdermal route of administration of a very active anti malarial drug whose use is limited by its toxicological effects. Therefore, a Transdermal Therapeutic System (TTS) containing primaquine (PQ) was investigated.

PQ is almost the only drug active against both blood and hepatic (acute and chronic, i. e. hypnozoites) stages. It is also able to prevent relapses of P. vivax infection. At present, PQ does not seem to be subject to induced drug resistance in the same way as other blood schizontocidal drugs (Nodiff et al., 1991). Des-

\footnotetext{
* Laboratoire de Physico-Chimie, Pharmacotechnie et Biopharmacie, URA CNRS 1218, Université Paris-Sud, 5, rue Jean Baptiste Clément, 92296 Chatenay-Malabry Cedex, France.

** Laboratório de Desenvolvimento Galênico, Faculdade de Farmácia, Universidade Federal do Rio Grande do Sul, Av. Ipiranga 2752, Porto Alegre RS, Brazil, CEP 90000.

*** Laboratoire de Biologie Parasitaire, Muséum National d'Histoire Naturelle, 61, rue Buffon, 75005 Paris, France.

Correspondence : G. Couarraze.
}

pite its activity, the use of PQ as a curative drug as well as a prophylactic agent is limited by its side effects, mainly at higher dosages to destroy asexual blood parasites during malaria attack. The most important of these side effects are the development of methaemoglobinaemia, a haemolytic anaemia, especially in people with G6PD deficiency precluding the use of $\mathrm{PQ}$ in this group, and gastrointestinal disturbances (Clyde, 1981). In addition, recent papers report effectiveness of PQ as a prophylactic drug against falciparum and vivax malaria (Baird, 1995; Fryauff, 1995; Weiss, 1995).

In order to evaluate the activity of this drug administered by the transdermal route, two rodent malaria models were used. Plasmodium yoelii nigeriensis and Plasmodium vinckei petteri were chosen because of their differences in chloroquine sensitivity. The results of activity on the asexual blood stage of the parasite are discussed with respect to the drug plasma profile.

The preliminary results described below showed that the transdermal route for primaquine administration is promising, demonstrating high activity towards different rodent malaria strains associated with a stedy drug plasma level. 


\section{MATERIALS AND METHODS}

\section{MATERIALS}

$\mathrm{P}$ rimaquine diphosphate was purchased from Sigma Chimie (France) and primaquine free base was obtained in our laboratory by extraction with organic solvent. The TTS formulation components used were a mixture of propylene glycol dicaprylate/caprate as a vehicle $\left(\right.$ Miglyol $^{\circledR}$ 840) provided by Hüls (Germany), an antioxidant $(+) \alpha$-tocopherol purchased from Sigma Chimie (France), ethyl cellulose polymer (Dow Chemical Company, Netherlands) with diethyl phthalate (Prolabo, France) as plasticizers and a pressure-sensitive adhesive acrylic resin, Durotak $^{\circledR} 2802287$ (National Starch \& Chemical, France). Ketoprofen was used as internal standard for HPLC assay. All other chemicals and solvents used were of reagent grade or HPLC quality. Male Swiss mice, weighing 24-26 g (Iffa Credo, France), were used. Two strains of rodent malaria parasites were chosen for this study, Plasmodium yoelii nigeriensis and Plasmodium vinckei petteri (strain $106 \mathrm{hW}$ ).

\section{METHODS}

Application of TTS device

TTS formulations were prepared as described by Mayorga et al. (1996). After the dorsal hair had been cut and shaved, taking care to avoid damage to the surface of the skin, the $1 \mathrm{~cm}^{2}$ patch containing PQ (15 mg) was stuck on the back of each mouse. This represented the start point of experiment (time $0 \mathrm{~h}$ ).

Determination of drug plasma concentration profile A preliminary evaluation of primaquine plasma levels following transdermal administration was carried out. The complete time-course study was obtained with four groups of four mice, where each one group corresponds with a single point on the drug plasma concentration profile. Blood samples were collected from the intraorbital sinus vein at 12, 24, 48 and 72 hours after the $1 \mathrm{~cm}^{2}$ patch application $(15 \mathrm{mg}$ of $P Q)$. The plasma was separated by centrifugation (3,000 rpm, $10 \mathrm{~min})$ and was kept in aluminium foilcovered Eppendorf tubes at $-20^{\circ} \mathrm{C}$ until analysis.

Plasma drug assay

For the determination of drug concentrations in plasma samples, $0.2 \mathrm{ml}$ of acetonitrile containing $4 \mu \mathrm{g} / \mathrm{mL}$ of ketoprofen as internal standard was added to $0.2 \mathrm{ml}$ of plasma. After vortexing for one minute, the mixture was centrifuged at $10,000 \mathrm{rpm}$ for 10 minutes. The supernatant was used for drug assay by high performance liquid chromatography. The analytical system (Waters 501) was equipped with an automatic sampler injector (Waters 712 WISP), a variable wavelength UV detector (Waters 484) and a reversed phase column (C8, $4 \times 125 \mathrm{~mm}$, particle size, $5 \mu \mathrm{m})$. The mobile phase of the HPLC system was composed of $7 \mathrm{~mm}$ monochloroacetic acid, $0.5 \mathrm{~mm}$ 1-decanosulfonic acidacetonitrile-methanol (56:24:20, v/v) (Dean et al., 1994). With a flow rate $1.5 \mathrm{ml} / \mathrm{min}$, peaks were detected by UV absorbance at $254 \mathrm{~nm}$.

\section{Infection of mice with Plasmodium parasites}

Four groups of three animals receiving patches were infected by intraperitoneal inoculation of $10^{6}$ of either Plasmodium yoelii nigeriensis or Plasmodium vinckei petteri - infected mouse erythrocytes at different intervals after patch application. The first group received the parasite at the same time of patch (T0) and the three others at T24, T48 or T72 hours after patch application. Each group was compared with a control group which did not receive a TTS device for evaluation of the activity of primaquine after transdermal application. Afterwards, the parasitaemia was evaluated over one month by a prepatency test (Warhust et al., 1968), i. e., number of days before parasitaemia reached $1 \%$. In order to evaluate a TTS containing a lower load of PQ $\left(5 \mathrm{mg} / \mathrm{cm}^{2}\right)$, a similar experiment was performed. In this case, the prepatency test was carried out after infection of mice at the same time as either 0.5 or $1 \mathrm{~cm}^{2}$ patch application.

\section{RESULTS}

\section{DETERMINATION}

OF DRUG PLASMA CONCENTRATION PROFILE

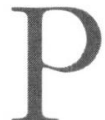
lasma levels of PQ following single TTS patch application were determined in healthy mice 12, 24, 48 and 72 hours after the $1 \mathrm{~cm}^{2}$ patch application (loaded at $15 \mathrm{mg} / \mathrm{cm}^{2}$ ). The effective dose of PQ was $4.17 \mathrm{mg}$ (approximately $30 \%$ of patch content). The plasma concentration profile is shown in Figure 1.

\section{ACTIVITY OF HIGH DOSE TTS (15 MG/ $\left.\mathrm{CM}^{2}\right)$} ON THE BLOOD STAGES OF RODENT MALARIA

\section{Plasmodium vinckei petteri}

In this experiment, patch application took place at the time 0 hour and parasites were inoculated at 0, 24, 48 and 72 hours. No mice became infected during the 30day follow-up. In control mice the parasitaemia reached $1 \%$ after 24 hours.

\section{Plasmodium yoelii nigeriensis}

The same protocol as that described above was used in this experiment. In this case, only the group that received parasite inoculation at 72 hours after device 


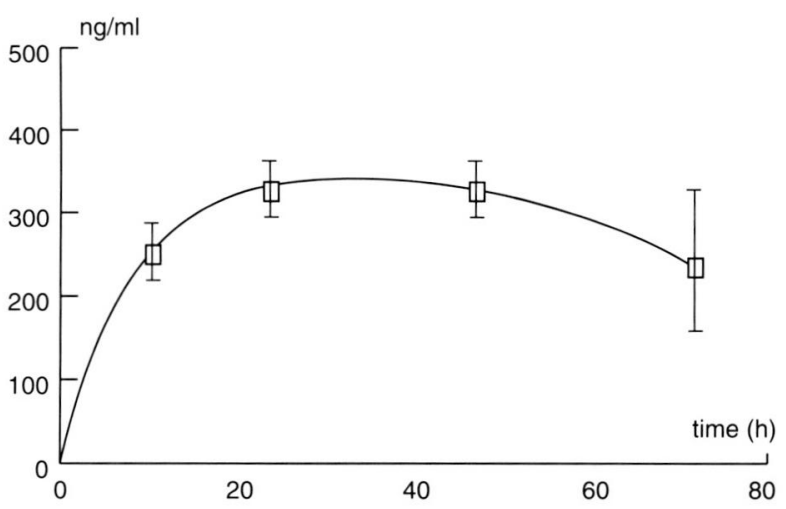

Fig. 1. - Plasma levels of PQ following single TTS patch application $\left(15.0 \mathrm{mg} / \mathrm{cm}^{2}\right)$. Each point on the drug plasma concentration profile corresponds to a four mice group.

application developed the disease, with a long prepatent period (21 days). The corresponding control group showed the same parasitaemia after only 24 hours.

\section{ACTIVITY OF LOWER-LOAD TTS ( $5 \mathrm{MG} / \mathrm{CM}^{2}$ )} ON THE BLOOD STAGES OF RODENT MALARIA

In this experiment intraperitoneal inoculation of $10^{6}$ Plasmodium yoelii nigeriensis - infected mouse erythrocytes and patch application were done simultaneously, i. e. at 0 hour. For comparison of parasitaemia, a control group was also inoculated with the parasites. The control group reached a parasitaemia of $1 \%$ within 24 hours. Mice groups treated with a 0.5 and $1 \mathrm{~cm}^{2}$ patch reached the same parasitaemia in 48 hours and 6 days, respectively.

\section{DISCUSSION}

$\mathrm{F}$ rom the plasma concentration data it was observed that the TTS device was able to deliver primaquine through the skin, mantaining a constant plasma concentration for about 60 hours. During this period, the sustained PQ concentration was around $300 \mathrm{ng} / \mathrm{ml}$. This value is much higher than the therapeutic plasma level at the man $(30 \mathrm{ng} / \mathrm{ml})$ and probably too high in relation to toxic concentration. Moreover, this result shows that the administration route investigated seemed to be able to deliver PQ in a way which would allow prolonged activity. However, further optimization of TTS patch to achieve lower plasma levels will be necessary. In addition, it would be interesting to study the effect of parasitemia on the bioavailability of PQ after transdermal administration to obtain a more complete information about this route of administration in the rodent malaria model. In this preliminary study we compared the activity of primaquine delivered from a TTS device on two dif- ferent rodent malaria strains. P. vinckei petteri is a very synchronous strain (Montalvo-Alvarez et al., 1988) and very sensitive to chloroquine (Cambie et al., 1991) producing very few latent merozoites. In contrast, $P$. yoelii nigeriensis is highly chloroquine-resistant (Peters and Robinson, 1987). It is an asynchronous strain and produces many latent merozoites which are chloroquine resistant.

Our results show that $\mathrm{PQ}$ is, like choroquine, more effective on P. v. petteri than P. y. nigeriensis. However, its activity towards P. $y$. nigeriensis is relatively high. It is well assumed that side effects reduction of a drug can be obtained by decrease of plasma drug concentration. Thus, after verification that high plasma levels of PQ could be achieved after device application, we were interested in the evaluation of a lower-load TTS patch $\left(5 \mathrm{mg} / \mathrm{cm}^{2}\right)$ after inoculation of $10^{6}$ parasites of Plasmodium yoelii nigeriensis. The sensitivity of plasma drug assay did not permit the determination of the plasma drug profile following application of this lowerload device. However, from physico-chemical data obtained from in-vitro experiments (study under investigation) we observed that a dose reduction from $15 \mathrm{mg} / \mathrm{cm}^{2}$ to $5 \mathrm{mg} / \mathrm{cm}^{2}$ produces a high reduction of percutaneous flux of PQ (ten fold aproximately). Thus, we can expect a lower plasma concentration of $\mathrm{PQ}$ after lower-load patch administration. In addition, the prepatent period observed with a $1 \mathrm{~cm}^{2}$ lower-load patch was also long, indicating that therapeutic levels of PQ had been obtained in the plasma.

In conclusion, it seems that this administration route is efficient for the elimination of intraerythrocytic stages but is not able to eliminate latent merozoites. Moreover, we have shown the potential use of the transdermal route for primaquine delivery in the treatment of asynchronous and chemioresistant rodent malaria strains by using a prolonged action controlled delivery device. Finally, we consider that further studies will be necessaries to determine the activity of PQ patch on intrahepatic stages to evaluate the potential of this system for prophylaxis against malaria.

\section{ACKNOWLEDGEMENTS}

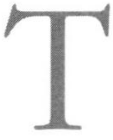
his study was carried out with the support of an international scientific program coordinated, in Brazil and France respectively, by the CAPES and COFECUB.

\section{REFERENCES}

Baird J.K., Fryauff D.J., Basri H., Bangs M.J., Subianto B., Wiady I., Purnomo, Leksana B., Masbar S., Richie T.L., Jones T.R., Tjitra E., Wignall F.S. \& Hoffman S.L. Primaquine 
for Prophylaxis against Malaria among Nonimune Transmigrants in Irian Jaya, Indonesia. American Joumal of Tropical Medicine and Hygiene, 1995, 52, 479-484.

Cambie G., Caillard V., Beauté-Laffite A., Ginsburg H., ChaBAUD A.G. \& Landau I. Chronotherapy of Malaria: Identification of Drug Sensitive Stage of Parasite and Timing of Drug Delivery for Improved Therapy. Annales de Parasitologie Humaine et Comparée, 1991, 66, 14-21.

Clyde D.F. Clinical Problems associated with the use of Primaquine as a Tissue Schizontocidal and Gametocytocidal Drug. Bulletin of the World Health Organization, 1981, 59, 391-395.

Dean R.A., Ochieng W., Black J., Queener S.F., Bartlett M.S. \& Dumaual N.G. Simultaneous Determination of Primaquine and Carboxyprimaquine in Plasma using High-Performance Liquid Chromatography with Electrochemical Detection. Journal of Chromatography B, 1994, 655, 8996.

Fryauff D.J., Baird J.K., Basri H., Sumawinata I., Purnomo, Richie T.L., Ohrt C.K., Mouzin E., Church C.J., Richards A.L., Subianto B., Sandjaja B., Wignall F.S. \& Hoffman S.L. Randomised Placebo-controlled Trial of Primaquine for Prophylaxis of Falciparum and Vivax Malaria. Lancet, 1995, 346, 1190-1193.

Mayorga P., Puisieux F. \& Counaraze G. Formulation Study of a Transdermal Delivery System of Primaquine. International Journal of Pharmaceutics, 1996, 132, 71-79.

Montalvo-Alvarez A., Landau I., Baccam D., Chabaud A.G. \& GINSBURG H. Experimental Modifications of the Circadian Rhythm of Plasmodium vinckei petteri following Cryopreservation; Probable Resistance of the Merozoite to Thawing. Comptes Rendus de l'Académie des Sciences de Paris, 1988, 307, 5-10.

Nodiff E.A., Chatterjee S. \& Musallam H.A. Antimalarial Activity of the 8-Aminoquinolines, in: Ellis G.P., West G.P. (Eds.) Progress in Medicine Chemistry, Vol. 28. Elsevier Science Publishers, 1991, 1-40.

Peters W. \& Robinson B.L. The activity of Primaquine and Its Possible Metabolites Against Rodent Malaria, in: Wernsdofer W.H. and Trigg P.I. (Eds.) Primaquine: Pharmacokinetics, Metabolism, Toxicity and Activity, UNDP/WORLD BANK/WHO, 1987, 93-101

Warhust D.C. \& Folwell R.O. Measurement of the Growth Rate of the Erythrocytic Stages of Plasmodium berghei and comparisons of the Potency of inocula after various treatments. Annals of Tropical Medicine and Parasitology, 1968, 62, 349-360.

Weiss W.R., Oloo A.J., Johnson A., Koech D. \& Hoffman S.L. Daily Primaquine is Effective for Prophylaxis against Falciparum Malaria in Kenya: Comparison with Mefloquine, Doxycycline, and Chloroquine plus Proguanil. The Journal of Infectious Diseases, 1995, 171, 1569-1575.

Reçu le 26 novembre 1996 Accepté le 30 janvier 1997 